\title{
KINEMATIC ANALYSIS OF MONO-MOBILE MECHANICAL SYSTEM ACTUATED BY MOTOR TETRAD RRR-TA-RRR
}

\author{
Ileana Dugaesescu ${ }^{1}$, Lucretia Popa ${ }^{2}$, Stefan Moise ${ }^{3}$, Victor Moise ${ }^{1}$, Vasilica Stefan $^{2}$, Alexandra Rotaru ${ }^{1}$ \\ ${ }^{1}$ University Politehnica of Bucharest, Romania; ${ }^{2}$ National Institute of Research-Development for \\ Machines and Installations Designed to Agriculture and Food Industry, Romania; \\ ${ }^{3}$ Etudes et Productions Schlumberger, France \\ ileana_d1@yahoo.com, lucretia_popa@yahoo.com, stef_moise@yahoo.fr, valle_vali@yahoo.com, \\ alexandra.rotaru11@gmail.com
}

\begin{abstract}
The mono - mobile mechanical systems are composed of an active modular group and one or more passive modular groups (dyad, triad etc.). To calculate the kinematic parameters of active modular groups there can be used methods such as the contour method, matrix method, grapho-analytical method, graphics method etc. In the case of solving the positions of the complex mechanisms as a whole, systems with a large number of equations, usually non-linear, are obtained. For solving these systems of equations the function matrix of the system is required, the matrix, which elements are obtained in a numerical or analytical way. The number of equations is very large, and the size of the functional matrix is very large, which leads to a large number of operations to obtain the inverse matrix. This paper presents a procedure for the kinematic analysis of an active modular group motor tetrad RRR-Ta-RRR type. To calculate the kinematic parameters (positions, angular velocities and accelerations) the contour method is used. The active modular group RRR-Ta-RRR has two independent kinematic contours, making it particularly effective in operating various mobile mechanical systems. The kinematic performances of the mechanisms, in which this modular group is found, are very high, the numerical solution of the system of non-linear equations of positions is simple, the convergence is rapid and the calculation precision desired can be controlled very easily. As examples of the use of active modular group RRR-Ta-RRR or other active modular groups (motor dyad, motor triad) can be mentioned: actuation of various lifting systems (actuating mechanism of a crank with articulated bars, actuating mechanism of a crank with articulated bars and gears), actuation of different folding tables, actuation of the gripping mechanisms used in industrial robots, etc.
\end{abstract}

Keywords: active modular group, mechanical system, kinematic analysis.

\section{Introduction}

The main objective of this paper is to present the procedure for calculating the kinematic parameters of an active modular group. The active modular group is used to activate the mechanical systems. The equations for kinematic analysis of the active modular group RRR-Ta-RRR [1-11] are written using the contour method [8]. As an example of calculation a lifting mechanism is analyzed, which has in its structure a motor tetrad and two RRR types. For kinematic analysis of the mechanism we used calculation procedures written by the authors in the MATLAB syntax. To create a clearer image how the mechanism works, the authors of the paper have also compiled animation computational procedures, and this animation has led to the theoretical data being confirmed.

\section{Materials and methods}

Figure 1 presents the active modular group named motor tetrad [5-9;12].

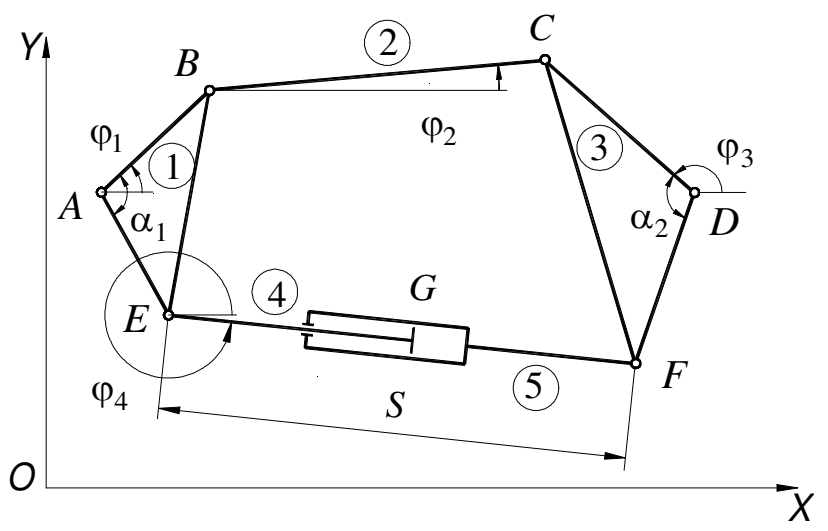

Fig.1. Kinematic scheme of motor tetrad 
The active modular group RRR-T $\mathrm{T}_{\mathrm{a}}-\mathrm{RRR}$, formed by five mobile elements and seven lower joints, has one degree of mobility.

To calculate the kinematic parameters of this active modular group the following are known: the length of all kinematic elements, positions, velocities and accelerations of points $A, D, G$ and the approximate coordinates of joints B, C, E and F. (Table 1) [5-9;12].

Table 1

\section{Input data of $R R R-T_{a}-R R R$ active modular group}

\begin{tabular}{|l|c|}
\hline \multicolumn{1}{|c|}{ Description } & Parameters \\
\hline Length of kinematic elements & $A B, A E, B E, B C, C D, D F, C F$ \\
\hline Coordinates of points $A$ and $D$ & $X A, Y A, X D, Y D$ \\
\hline Projections of linear velocities of points $A$ and $D$ & $\dot{X} A, \dot{Y} A, \dot{X} D, \dot{Y} D$ \\
\hline Projections of linear accelerations of points $A$ and $D$ & $\ddot{X} A, \ddot{Y} A, \ddot{X} D, \ddot{Y} D$ \\
\hline Variable parameter in the active joint $G$ & $S$ \\
\hline Linear relative velocity of the active joint $G$ & $\dot{S}$ \\
\hline Linear relative acceleration of the active joint $G$ & $\ddot{S}$ \\
\hline $\begin{array}{l}\text { Approximate coordinates of the internal joints } B, C, \\
E \text { and } F\end{array}$ & $X B, Y B, X C, Y C, X E, Y E, X F, Y F$ \\
\hline
\end{tabular}

In Table 2, the dependent kinematic parameters that will be determined are presented [5-9;12].

Output data of RRR-T $T_{\mathrm{a}}-\mathrm{RRR}$ active modular group

Table 2

\begin{tabular}{|l|c|}
\hline \multicolumn{1}{|c|}{ Description } & Parameters \\
\hline Angles between the axis OX and the vectors $\overline{A B}, \overline{B C}, \overline{D C}, \overline{E F}$ & $\varphi_{1}, \varphi_{2}, \varphi_{3}, \varphi_{4}$ \\
\hline Angular velocities of the links 1,2,3 and 4(5) & $\dot{\varphi}_{1}, \dot{\varphi}_{2}, \dot{\varphi}_{3}, \dot{\varphi}_{4}$ \\
\hline Angular accelerations of the links 1,2,3 and 4(5) & $\ddot{\varphi}_{1}, \ddot{\varphi}_{2}, \ddot{\varphi}_{3}, \ddot{\varphi}_{4}$ \\
\hline
\end{tabular}

\section{Analysis of the positions of active modular group $R R R-T_{a}-R R R$}

The vector equations $[5,6,7,8,9,10]$ :

$$
\overline{O A}+\overline{A B}+\overline{B C}=\overline{O D}+\overline{D C} ; \overline{O A}+\overline{A E}+\overline{E F}=\overline{O D}+\overline{D F} \text {, }
$$

are projected on the axis of the coordinate system and the following four non - linear equations are obtained:

$$
\left\{\begin{array}{l}
A B \cos \varphi_{1}+B C \cos \varphi_{2}-C D \cos \varphi_{3}+X A-X D=0 \\
A B \sin \varphi_{1}+B C \sin \varphi_{2}+C D \sin \varphi_{3}+Y A-Y D=0 \\
A E \cos \left(\varphi_{1}-\alpha_{1}\right)+S \cos \varphi_{4}-D F \cos \left(\varphi_{3}+\alpha_{2}\right)+X A-X D=0 \\
A E \sin \left(\varphi_{1}-\alpha_{1}\right)+S \sin \varphi_{4}-D F \sin \left(\varphi_{3}+\alpha_{2}\right)+Y A-Y D=0
\end{array}\right.
$$

The unknowns of the system of equations (2) are $\varphi_{1}, \varphi_{2}, \varphi_{3}$ and $\varphi_{4}$.

To solve the non-linear system of equations (2) the iterative Newton-Raphson method is used starting from the given initial solution.

The functions of the non - linear system of equations (2) are: 


$$
\begin{aligned}
& f_{1}\left(\varphi_{1}, \varphi_{2}, \varphi_{3}, \varphi_{4}\right)=A B \cos \varphi_{1}+B C \cos \varphi_{2}-C D \cos \varphi_{3}+X A-X D \\
& f_{2}\left(\varphi_{1}, \varphi_{2}, \varphi_{3}, \varphi_{4}\right)=A B \sin \varphi_{1}+B C \sin \varphi_{2}-C D \sin \varphi_{3}+Y A-Y D \\
& f_{3}\left(\varphi_{1}, \varphi_{2}, \varphi_{3}, \varphi_{4}\right)=A E \cos \left(\varphi_{1}-\alpha_{1}\right)+S \cos \varphi_{4}-D F \cos \left(\varphi_{3}+\alpha_{2}\right)+X A-X D \\
& f_{4}\left(\varphi_{1}, \varphi_{2}, \varphi_{3}, \varphi_{4}\right)=A E \sin \left(\varphi_{1}-\alpha_{1}\right)+S \sin \varphi_{4}-D F \sin \left(\varphi_{3}+\alpha_{2}\right)+Y A-Y D
\end{aligned}
$$

The system solution at the $(i+1)$ iteration has the form:

$$
\left\|\begin{array}{c}
\varphi_{1} \\
\varphi_{2} \\
\varphi_{3} \\
\varphi_{4}
\end{array}\right\|^{i+1}=\left\|\begin{array}{c}
\varphi_{1} \\
\varphi_{2} \\
\varphi_{3} \\
\varphi_{4}
\end{array}\right\|^{i}-W^{-1}\left(\varphi_{1}^{i}, \varphi_{2}^{i}, \varphi_{3}^{i}, \varphi_{4}^{i}\right)\left\|\begin{array}{l}
f_{1}\left(\varphi_{1}^{i}, \varphi_{2}^{i}, \varphi_{3}^{i}, \varphi_{4}^{i}\right) \\
f_{2}\left(\varphi_{1}^{i}, \varphi_{2}^{i}, \varphi_{3}^{i}, \varphi_{4}^{i}\right) \\
f_{3}\left(\varphi_{1}^{i}, \varphi_{2}^{i}, \varphi_{3}^{i}, \varphi_{4}^{i}\right) \\
f_{4}\left(\varphi_{1}^{i}, \varphi_{2}^{i}, \varphi_{3}^{i}, \varphi_{4}^{i}\right)
\end{array}\right\|,
$$

where

$$
W=\left\|\begin{array}{cccc}
-A B \sin \varphi_{1} & -B C \sin \varphi_{2} & C D \sin \varphi_{3} & 0 \\
A B \cos \varphi_{1} & B C \cos \varphi_{2} & C D \cos \varphi_{3} & 0 \\
-A E \sin \left(\varphi_{1}-\alpha_{1}\right) & 0 & D F \sin \left(\varphi_{3}+\alpha_{2}\right) & -S \sin \varphi_{4} \\
A E \cos \left(\varphi_{1}-\alpha_{1}\right) & 0 & -D F \cos \left(\varphi_{3}+\alpha_{2}\right) & S \cos \varphi_{4}
\end{array}\right\|,
$$

represents the matrix of the partial derivatives of the system functions in relation to the parameters $\varphi_{1}$, $\varphi_{2}, \varphi_{3}$ and $\varphi_{4}$.

The initial solution is:

$$
\begin{aligned}
& \phi_{1}^{(0)}=\operatorname{atan} 2(Y B-Y A, X B-X A) ; \phi_{3}^{(0)}=\operatorname{atan} 2(Y C-Y D, X C-X D) \\
& \phi_{2}^{(0)}=\operatorname{atan} 2(Y C-Y B, X C-X B) ; \phi_{4}^{(0)}=\operatorname{atan} 2(Y F-Y E, X F-X E),
\end{aligned}
$$

where $X B, Y B, X C, Y C, X E, Y E, X F, Y F$ are the approximate coordinates of internal joints $B, C$, $E$ and $F$.

The iterative process stops, when the difference of two consequently calculated solutions is smaller than $\varepsilon$ (imposed value) meaning:

$$
\|\phi\|^{(i+1)}-\|\phi\|^{(i)} \leq \varepsilon
$$

\section{Analysis of the velocities of active modular group $R R R-T_{a}-R R R$}

The system of position equations (2), with respect to the time, is derived and the following system is obtained [5-9;12]:

$$
\left\{\begin{array}{l}
-A B \sin \varphi_{1} \dot{\varphi}_{1}-B C \sin \varphi_{2} \dot{\varphi}_{2}+C D \sin \varphi_{3} \dot{\varphi}_{3}=A 1 \\
A B \cos \varphi_{1} \dot{\varphi}_{1}+B C \cos \varphi_{2} \dot{\varphi}_{2}-C D \cos \varphi_{3} \dot{\varphi}_{3}=A 2 \\
-A E \sin \left(\varphi_{1}-\alpha_{1}\right) \dot{\varphi}_{1}-S \sin \varphi_{4} \dot{\varphi}_{4}+D F \sin \left(\varphi_{3}+\alpha_{2}\right) \dot{\varphi}_{3}=A 3 \\
A E \cos \left(\varphi_{1}-\alpha_{1}\right) \dot{\varphi}_{1}+S \cos \varphi_{4} \dot{\varphi}_{4}+D F \cos \left(\varphi_{3}+\alpha_{2}\right) \dot{\varphi}_{3}=A 4
\end{array},\right.
$$

where

$$
A_{1}=X D-X A ; A_{2}=Y D-Y A ; A_{3}=k-S \cos \phi_{4} ; A_{4}=h-S \sin \phi_{4} .
$$

The system of equations (7) is linear and it has the unknowns $\dot{\varphi}_{1}, \dot{\varphi}_{2}, \dot{\varphi}_{3}, \dot{\varphi}_{4}$ so:

$$
\left\|\dot{\varphi}_{1}, \dot{\varphi}_{2}, \dot{\varphi}_{3}, \dot{\varphi}_{4}\right\|^{T}=W^{-1}\left\|A_{1} \quad A_{2} \quad A_{3} \quad A_{4}\right\|^{T}
$$




\section{Analysis of the accelerations of active modular group $R R R-T_{a}-R R R$}

Through derivation of the system of velocity equations (7), with respect to the time, the system of acceleration equations is obtained [5-9;12]:

$$
\left\{\begin{array}{l}
-A B \sin \varphi_{1} \ddot{\varphi}_{1}-B C \sin \varphi_{2} \ddot{\varphi}_{2}+C D \sin \varphi_{3} \ddot{\varphi}_{3}=B 1 \\
A B \cos \varphi_{1} \ddot{\varphi}_{1}+B C \cos \varphi_{2} \ddot{\varphi}_{2}-C D \cos \varphi_{3} \ddot{\varphi}_{3}=B 2 \\
-A E \sin \left(\varphi_{1}-\alpha_{1}\right) \ddot{\varphi}_{1}+D F \sin \left(\varphi_{3}+\alpha_{2}\right) \ddot{\varphi}_{3}-S \sin \varphi_{4} \ddot{\varphi}_{4}=B 3 \\
A E \cos \left(\varphi_{1}-\alpha_{1}\right) \ddot{\varphi}_{1}-D F \cos \left(\varphi_{3}+\alpha_{2}\right) \ddot{\varphi}_{3}+S \cos \varphi_{4} \ddot{\varphi}_{4}=B 4
\end{array}\right.
$$

with the following unknwons $\ddot{\varphi}_{1}, \ddot{\varphi}_{2}, \ddot{\varphi}_{3}, \ddot{\varphi}_{4}$, where:

$$
\left\{\begin{array}{l}
B 1=A B \cos \varphi_{1} \dot{\varphi}_{1}^{2}+B C \cos \varphi_{2} \dot{\varphi}_{2}^{2}-C D \cos \varphi_{3} \dot{\varphi}_{3}^{2}+\ddot{X} D-\ddot{X} A \\
B 2=A B \sin \varphi_{1} \dot{\varphi}_{1}^{2}+B C \sin \varphi_{2} \dot{\varphi}_{2}^{2}-C D \sin \varphi_{3} \dot{\varphi}_{3}^{2}+\ddot{Y} D-\ddot{Y} A \\
B 3=A E \cos \left(\varphi_{1}-\alpha_{1}\right) \cdot \dot{\varphi}_{1}^{2}+\left(S \dot{\varphi}_{4}^{2}-\ddot{S}\right) \cos \varphi_{4}+2 \dot{S} \dot{\varphi}_{4}-D F \cos \left(\varphi_{3}+\alpha_{2}\right) \dot{\varphi}_{3}^{2}+\ddot{X} D-\ddot{X} A \\
B 4=A E \sin \left(\varphi_{1}-\alpha_{1}\right) \cdot \dot{\varphi}_{1}^{2}+\left(S \dot{\varphi}_{4}^{2}-\ddot{S}\right) \sin \varphi_{4}-2 \dot{S} \dot{\varphi}_{4}-D F \sin \left(\varphi_{3}+\alpha_{2}\right) \dot{\varphi}_{3}^{2}+\ddot{Y} D-\ddot{Y} A
\end{array}\right.
$$

The solution of the system of equations (10) is:

$$
\left\|\ddot{\varphi}_{1}, \ddot{\varphi}_{2}, \ddot{\varphi}_{3}, \ddot{\varphi}_{4}\right\|^{T}=W^{-1}\left\|B_{1} \quad B_{2} \quad B_{3} \quad B_{4}\right\|^{T} .
$$

In Figure 2 the kinematic scheme of a crank with the motortetrad is presented.

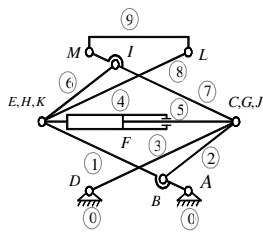

Fig. 2. Kinematic scheme of crank with motor tetrad

In Figure 3 the structural scheme corresponding to the mechanical system from Figure 2 is presented. The structural model has a binary element for the frame and it is composed by the RRR-T $\mathrm{a}^{-}$ RRR active modular group and two passive groups of RRR dyad type.

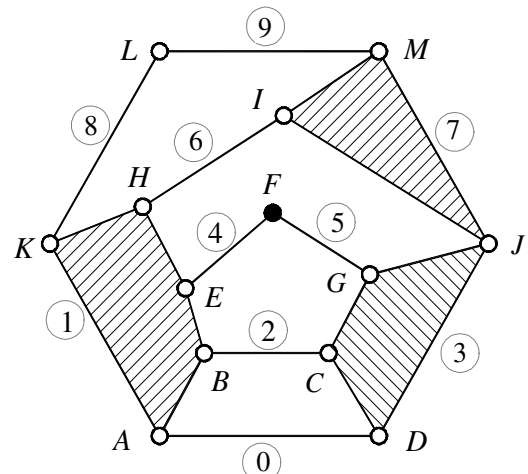

Fig. 3. Structural scheme of crank with motor tetrad

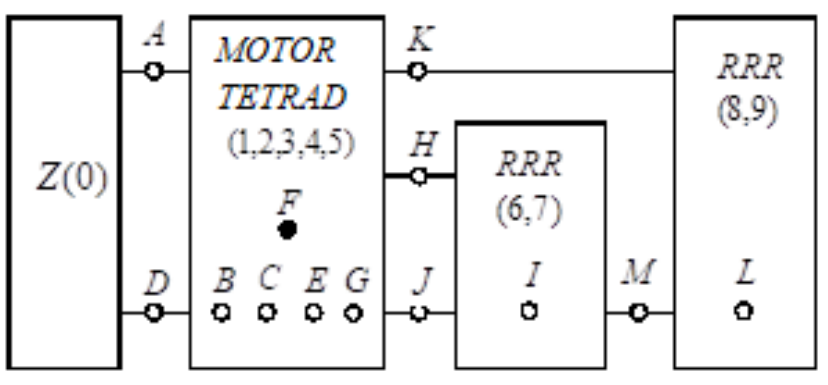

Fig. 4. Multipolar scheme of crank with motor tetrad 
In Figure 4 the multipolar scheme corresponding to the structural scheme from Fig. 3 is presented. The actuating pair $(\mathrm{F})$ is drawn as a black dot.

\section{Results and discussions}

To determine the kinematic parameters of the mechanism elements, the following data were considered: $\quad A B=0.061 \mathrm{~m}, \quad A E=0.280 \mathrm{~m}, \quad B C=0.1598 \mathrm{~m} ; \quad C D=0.280 \mathrm{~m}, \quad B E=A E-A B$, $J M=0.280 \mathrm{~m}, J I=B E, H I=B C, K L=A E, M L=0.180 \mathrm{~m}, X A=0.0 \mathrm{~m}, Y A=0.0 \mathrm{~m}, X D=-0.180 \mathrm{~m}$, $Y D=0.0 \mathrm{~m}, S=0.270 \mathrm{~m}$, stroke_hyd_cyl $=0.098 \mathrm{~m}$, hyd_cyl speed $d C F / d t=-0.025 \mathrm{~m} \cdot \mathrm{s}^{-1}$, relative acceleration of the hydraulic cylinder $=0.0 \mathrm{~m} \cdot \mathrm{s}^{-2}$

Using the procedure for the motor tetrad the kinematic parameters of the mechanical system presented in Figure 2 are calculated. The values for the angles between the axis OX and the vectors $\overline{A B}, \overline{B C}, \overline{D C}, \overline{E F}$ are presented in Table 3 .

Table 3

Values of position parameters of the mechanical system

\begin{tabular}{|c|c|c|c|c|c|c|c|}
\hline Pos. & $\mathbf{0}$ & $\mathbf{1}$ & $\mathbf{2}$ & $\mathbf{3}$ & $\mathbf{4}$ & $\mathbf{5}$ & $\mathbf{6}$ \\
\hline $\boldsymbol{\varphi}_{\mathbf{1}}$ & 2.9266 & 2.8938 & 2.8640 & 2.8365 & 2.8108 & 2.7866 & 2.7635 \\
\hline $\boldsymbol{\varphi}_{\mathbf{2}}$ & 0.2698 & 0.3375 & 0.3936 & 0.4426 & 0.4866 & 0.5268 & 0.5641 \\
\hline $\boldsymbol{\varphi}_{\mathbf{3}}$ & 0.1999 & 0.2448 & 0.2823 & 0.3151 & 0.3444 & 0.3712 & 0.3958 \\
\hline $\boldsymbol{\varphi}_{\mathbf{4}}$ & -0.0112 & -0.0022 & 0.0036 & 0.0075 & 0.0103 & 0.0123 & 0.0136 \\
\hline Pos. & $\mathbf{7}$ & $\mathbf{8}$ & $\mathbf{9}$ & $\mathbf{1 0}$ & $\mathbf{1 1}$ & $\mathbf{1 2}$ & $\mathbf{1 3}$ \\
\hline $\boldsymbol{\varphi}_{\mathbf{1}}$ & 2.7413 & 2.7200 & 2.6993 & 2.6792 & 2.6596 & 2.6404 & 2.6217 \\
\hline $\boldsymbol{\varphi}_{\mathbf{2}}$ & 0.5990 & 0.6319 & 0.6630 & 0.6927 & 0.7211 & 0.7483 & 0.7744 \\
\hline $\boldsymbol{\varphi}_{\mathbf{3}}$ & 0.4188 & 0.4404 & 0.4606 & 0.4799 & 0.4981 & 0.5155 & 0.5321 \\
\hline $\boldsymbol{\varphi}_{\mathbf{4}}$ & 0.0143 & 0.0145 & 0.0143 & 0.0136 & 0.0127 & 0.0113 & 0.0097 \\
\hline Pos. & $\mathbf{1 4}$ & $\mathbf{1 5}$ & $\mathbf{1 6}$ & $\mathbf{1 7}$ & $\mathbf{1 8}$ & $\mathbf{1 9}$ & $\mathbf{2 0}$ \\
\hline $\boldsymbol{\varphi}_{\mathbf{1}}$ & 2.6032 & 2.5851 & 2.5672 & 2.5496 & 2.5321 & 2.5148 & 2.4977 \\
\hline $\boldsymbol{\varphi}_{\mathbf{2}}$ & 0.7997 & 0.8241 & 0.8477 & 0.8706 & 0.8928 & 0.9144 & 0.9355 \\
\hline $\boldsymbol{\varphi}_{\mathbf{3}}$ & 0.5480 & 0.5632 & 0.5779 & 0.5920 & 0.6055 & 0.6186 & 0.6312 \\
\hline $\boldsymbol{\varphi}_{\mathbf{4}}$ & 0.0077 & 0.0054 & 0.0028 & -0.0001 & -0.0032 & -0.0067 & -.00105 \\
\hline
\end{tabular}

The values for the angular velocities of the links 1, 2, 3 and 4 (5) are presented in Table 4.

Table 4

Angular velocities of the mechanical system

\begin{tabular}{|c|c|c|c|c|c|c|c|}
\hline Pos. & 0 & 1 & 2 & 3 & 4 & 5 & 6 \\
\hline$\dot{\varphi_{1}}=\omega 1$ & -0.7043 & -0.6363 & -0.5825 & -0.5411 & -0.5087 & -0.4826 & -0.4613 \\
\hline$\dot{\dot{\varphi}_{2}}=\boldsymbol{\omega} 2$ & 1.5520 & 1.2419 & 1.0633 & 0.9437 & 0.8563 & 0.7889 & 0.7348 \\
\hline$\dot{\varphi_{3}}=\boldsymbol{\omega} 3$ & 1.0240 & 0.8279 & 0.7106 & 0.6301 & 0.5703 & 0.5234 & 0.4853 \\
\hline$\dot{\dot{\varphi}_{4}}=\boldsymbol{\omega} 4$ & 0.2370 & 0.1431 & 0.0966 & 0.0679 & 0.0477 & 0.0323 & 0.0198 \\
\hline Pos. & 7 & 8 & 9 & 10 & 11 & 12 & 13 \\
\hline$\dot{\dot{\varphi}_{1}}=\boldsymbol{\omega} 1$ & -0.4435 & -0.4286 & -0.4158 & -0.4047 & -0.3952 & -0.3868 & -0.3795 \\
\hline$\dot{\dot{\varphi}_{2}}=\boldsymbol{\omega} 2$ & 0.6901 & 0.6524 & 0.6199 & 0.5916 & 0.5666 & 0.5444 & 0.5243 \\
\hline$\dot{\varphi_{3}}=\boldsymbol{\omega} 3$ & 0.4535 & 0.4263 & 0.4027 & 0.3819 & 0.3633 & 0.3466 & 0.3315 \\
\hline$\dot{\dot{\varphi}_{4}}=\boldsymbol{\omega} 4$ & 0.0091 & -0.0002 & -0.0086 & -0.0163 & -0.0236 & -0.0305 & -0.0371 \\
\hline Pos. & 14 & 15 & 16 & 17 & 18 & 19 & 20 \\
\hline$\dot{\varphi_{1}}=\omega 1$ & -0.3731 & -0.3674 & -0.3624 & -0.3580 & -0.3541 & -0.3507 & -0.3477 \\
\hline$\dot{\varphi_{2}}=\boldsymbol{\omega} 2$ & 0.5061 & 0.4895 & 0.4743 & 0.4603 & 0.4473 & 0.4351 & 0.4238 \\
\hline$\dot{\dot{\varphi}_{3}}=\boldsymbol{\omega} 3$ & 0.3176 & 0.3048 & 0.2930 & 0.2820 & 0.2717 & 0.2620 & 0.2529 \\
\hline$\dot{\varphi_{4}}=\omega 4$ & -0.0435 & -0.0497 & -0.0559 & -0.0621 & -0.0682 & -0.0744 & -0.0806 \\
\hline
\end{tabular}

The values for the angular accelerations of the links 1,2, 3 and 4 (5) are presented in Table 5. 
Angular accelerations of the mechanical system

Table 5

\begin{tabular}{|c|c|c|c|c|c|c|c|}
\hline Pos. & $\mathbf{0}$ & $\mathbf{1}$ & $\mathbf{2}$ & $\mathbf{3}$ & $\mathbf{4}$ & $\mathbf{5}$ & $\mathbf{6}$ \\
\hline$\ddot{\boldsymbol{\varphi}}_{1}=\boldsymbol{\varepsilon} 1$ & 1.4507 & 1.2506 & 0.9594 & 0.7449 & 0.5922 & 0.4813 & 0.3984 \\
\hline$\ddot{\boldsymbol{\varphi}}_{2}=\boldsymbol{\varepsilon} 2$ & -8.8132 & -4.5881 & -2.9137 & -2.0584 & -1.5539 & -1.2275 & -1.0020 \\
\hline$\ddot{\boldsymbol{\varphi}}_{3}=\boldsymbol{\varepsilon} 3$ & -5.4463 & -2.9705 & -1.9406 & -1.3990 & -1.0732 & -0.8592 & -0.7099 \\
\hline$\ddot{\boldsymbol{\varphi}}_{4}=\boldsymbol{\varepsilon} 4$ & -3.0928 & -1.4133 & -0.8644 & -0.6199 & -0.4901 & -0.4131 & -0.3639 \\
\hline Pos. & $\mathbf{7}$ & $\mathbf{8}$ & $\mathbf{9}$ & $\mathbf{1 0}$ & $\mathbf{1 1}$ & $\mathbf{1 2}$ & $\mathbf{1 3}$ \\
\hline$\ddot{\boldsymbol{\varphi}}_{1}=\boldsymbol{\varepsilon} 1$ & 0.3346 & 0.2845 & 0.2442 & 0.2113 & 0.1839 & 0.1608 & 0.1411 \\
\hline$\ddot{\boldsymbol{\varphi}}_{2}=\boldsymbol{\varepsilon} 2$ & -0.8386 & -0.7156 & -0.6204 & -0.5448 & -0.4836 & -0.4332 & -0.3911 \\
\hline$\ddot{\boldsymbol{\varphi}}_{3}=\boldsymbol{\varepsilon} 3$ & -0.6006 & -0.5179 & -0.4535 & -0.4021 & -0.3603 & -0.3258 & -0.2968 \\
\hline$\ddot{\boldsymbol{\varphi}}_{4}=\boldsymbol{\varepsilon} 4$ & -0.3309 & -0.3080 & -0.2919 & -0.2806 & -0.2727 & -0.2674 & 0.2642 \\
\hline Pos. & $\mathbf{1 4}$ & $\mathbf{1 5}$ & $\mathbf{1 6}$ & $\mathbf{1 7}$ & $\mathbf{1 8}$ & $\mathbf{1 9}$ & $\mathbf{2 0}$ \\
\hline$\ddot{\boldsymbol{\varphi}}_{1}=\boldsymbol{\varepsilon} 1$ & 0.1241 & 0.1093 & 0.0962 & 0.0845 & 0.0741 & 0.0646 & 0.0559 \\
\hline$\ddot{\boldsymbol{\varphi}}_{2}=\varepsilon 2$ & -0.3555 & -0.3250 & -0.2986 & -0.2756 & -0.2554 & -0.2374 & -0.2214 \\
\hline$\ddot{\boldsymbol{\varphi}}_{3}=\boldsymbol{\varepsilon} 3$ & -0.2723 & -0.2513 & -0.2331 & -0.2173 & -0.2033 & -0.1910 & -0.1800 \\
\hline$\ddot{\boldsymbol{\varphi}}_{4}=\boldsymbol{\varepsilon} 4$ & -0.2627 & -0.2626 & -0.2637 & -0.2659 & -0.2692 & -0.2733 & -0.2784 \\
\hline
\end{tabular}

The variation of the kinematic parameters of the mechanical system is presented in Figure 5.

a)

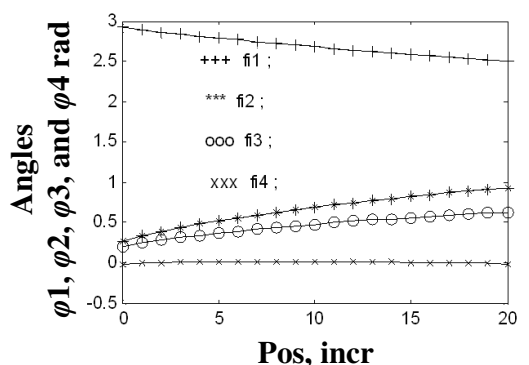

b)

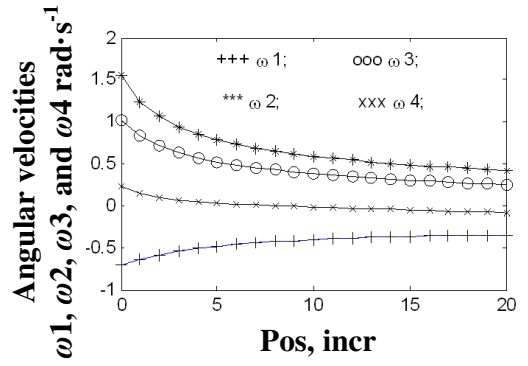

c)

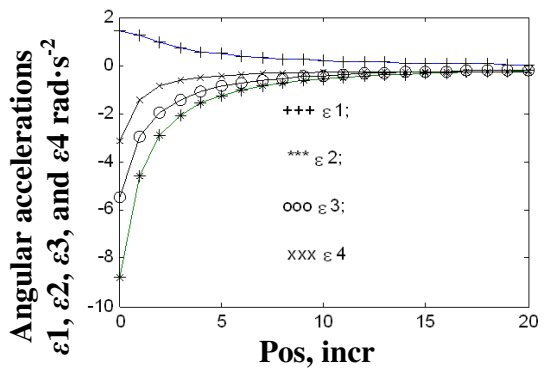

Fig. 5. Variations of kinematic parameters: $a$ - positions; $b$ - angular velocities; $\mathrm{c}$ - angular accelerations

\section{Conclusions}

The paper presents a procedure to calculate the kinematic parameters (positions, angular velocities and accelerations) for the active modular group named motor tetrad RRR-T $\mathrm{a}-\mathrm{RRR}$ using the closed loops method. Then, the kinematic analysis of a crank actuated by motor tetrad is presented. For the crank the structural and multipolar schemes and values of the kinematic parameters are presented.

The active modular group RRR- $\mathrm{T}_{\mathrm{a}}-\mathrm{RRR}$ can be used to actuate some mechanical systems, such as industrial machines and mechanisms, agricultural machinery etc.

The kinematic analysis of the mechanism in Figure 2 was done with the data obtained from the synthesis of the mechanism, so that the points $\mathrm{M}$ and $\mathrm{N}$ would move vertically for a certain distance required.

The kinematic analysis of the mechanism precedes its kinetostatic analysis, namely, determination of the reaction forces in the kinematic couplings and the driving force of the hydraulic cylinder, which will be done in the next research. 


\section{Acknowledgement}

This work was supported by a grant of the Romanian Research and Innovation Ministry, through Programme 1 - Development of the national research-development system, subprogramme 1.2 Institutional performance - Projects for financing excellence in RDI, contract No. 16PFE.

\section{References}

[1] Artobolevski I.I. Theorie des mecanismes et des machines. (Theory of Mechanisms and Machines). Moscow: Ed. Mir, 1977. 453 p. (In French).

[2] Demidovich B., Maron A.I. Éléments de calculnumérique. 2nd edition. Moscow: Ed. Mir, 1987. 717 p. (In French).

[3] Manolescu N., Kovacs Fr., Orănescu A. Teoria mecanismelor şi a maşinilor(The Mechanisms and Machines Theory). Ed.Didactică\&Pedagogică, Bucharest, 1972. (In Romanian).

[4] Moise V. Cinematica şi controlul mecanisme lor manipulatoare cu 4 grade de mobilitate (Kinematics and control of manipulating mechanisms with 4 degrees of mobility).PhD Thesis, Bucharest, 1986. (In Romanian).

[5] Moise V., Simionescu I., Ene M., Neacşa M., Tabără I.A., Analiza mecanisme loraplicate (Analysis of Applied Mechanisms). Bucharest. Ed.Printech, 2007 (In Romanian).

[6] Moise V., Simionescu I., Ene M., Rotaru Al. Analysis of planar mechanisms with articulated bars. Applications in MATLAB (Analizamecanismelor plane cu bare articulate. Aplicațiiîn MATLAB). Ed.Printech, Bucharest, 2015. (In Romanian).

[7] Pelecudi Chr. Precizia mecanismelor (The precision of the mechanisms). Ed.Academiei R.S.R., Bucharest, 1975. (In Romanian).

[8] Pelecudi Chr., Maroş D., Merticaru V., Pandrea N., Simionescu I. Mecanisme (Mechanisms). Ed.Didactică\&Pedagogică, Bucharest, 1985. (In Romanian).

[9] Simionescu I., Moise V. Mecanisme (Mechanisms). Ed.Tehnică, Bucharest, 1999. (In Romanian).

[10] Vâlcovici V., BălanȘt., Voinea R.Mecanicăteoretică (Theoretical mechanics), Ed.Tehnică, Bucharest, 1963. (In Romanian).

[11] Voinea R., Voiculescu D., Ceauşu V.Mecanică (Mechanics). Ed. Didactică\&Pedagogică, Bucharest, 1985. (In Romanian).

[12] Moise V., Maican E., Moise Şt. Numerical methods. Applications in MATLAB (Metodenumerice. Aplicațiîn MATLAB). Ed. Printech, Bucharest, 2016. (In Romanian). 